\title{
Simulation of Heat Radiation for High-power LED Liquid Packaging Dong-Sheng PENG ${ }^{*}$, Dan ZENG and Cong-Cong TAN
}

Key Laboratory of Optoelectronic Devices and Systems of Ministry of Education and Guangdong Province, Shenzhen University, Shenzhen 518060, China

E-mail:* pengdongsheng@163.com

Keywords: Simulation, Heat radiation, LED, Liquid packaging

\begin{abstract}
With the power of LED gradually ascend, LED lighting lamps' heat problems also increasingly exposed. The paper is around the study of high power LED packaging of liquid cooling. Through comparative analysis of DLC metal base, aluminum nitride ceramics and alumina ceramic thermal performance, it is found that traditional packaging junction temperature varies greatly, and liquid packaging junction temperature difference is small. Thus, heat is mainly dissipated through convection of liquid, and the difference of junction temperature is small.
\end{abstract}

\section{Introduction}

LEDs (Light Emitting Diodes) are the new competitive solidlighting devices in the twenty-first century. Compared with thetraditional light sources, LEDs have long lifetime, high reliability and efficiency. With the "energy saving, low-carbon economy characteristics, LED is the trend of the times as the "fourth generation"lighting, and it has been widely used in many applications. However, the LED chip junction temperature is a critical factor which restricts the LED light source to be used in the automotive headlight. Currently, the power of modern LED chip for light is above $1 \mathrm{~W}$, even up to $5 \mathrm{~W}$, and the area of chip is less than $1 \mathrm{~mm}^{2}$, corresponding to $100 \mathrm{~W} / \mathrm{cm}^{2}$ of heat flux, which will result in high chip junction temperature[1], and the high junction temperature will greatly lead to the dominant luminescence wavelength drift, the decline of the optical efficiency, as well as the degradation lifetime of the phosphor[2]. As a result, the abilityto thermally manage and reduce the chip junction temperature has become paramount in the overall development of LED automotive headlight[3]. In recent years, many researchers and the high-power LED manufacturers have launched a series of new enhanced LED chip cooling methods[4-7]. In this paper, the comparative analysis of the effection of DLC metal substrates, aluminum nitride ceramics, and alumina ceramic on the heat radiaion for high power LED traditional packaging and liquid packaging.

\section{Theoretical Model}

Heat produced by chip ration, convection by liquid and air are loaded in the sinulation. In generally, the photoelectric transformation efficiency of chip is $20 \%$. The changed heat between wall and liquid is shown as equation (1).

$$
Q=h \times A \times \Delta T
$$

Where h,A and $\Delta \mathrm{T}$ are surface delivered heat coefficient, delivered heat area and temperature difference between wall and liquid, respectively. The convection is coefficient is $10 \mathrm{w} / \mathrm{m}^{2 \circ} \mathrm{C}$, the room temperature is $25^{\circ} \mathrm{C}$.

The heat radiaion is simulated based on ANSYS finite analysis software. The array of chip on the base is $12 \times 12$,the power of all chips is $166 \mathrm{~W}$. Because the part of model is symmetric, the $1 / 4$ model is studied in the paper. The three dimensional eight panel point unit of SOLID70 is selected in the course of heat analysis. The R,G, B three based chip is simplified by a unit in the simplified figure of chip model, as shown in figure 1 . The size of chip is $1.5 \times 2 \times 0.01$. 


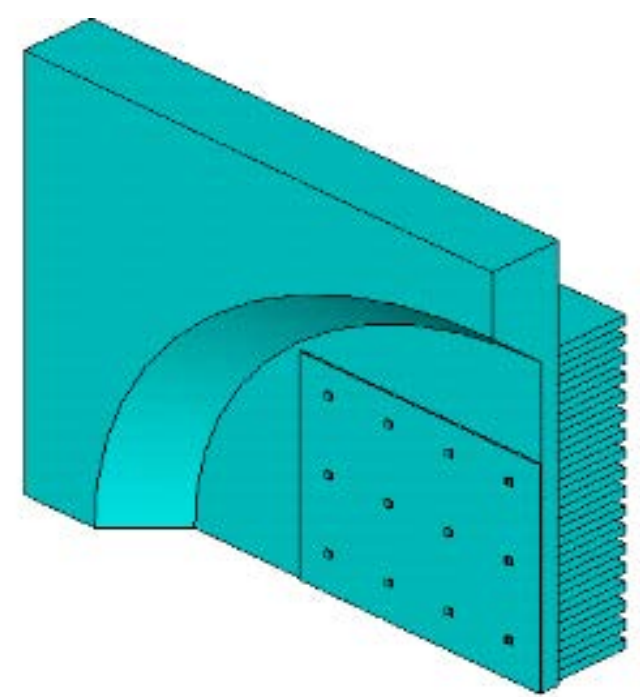

Fig. 1. Schematics of chip array on the base in $1 / 4$ model

\section{Results and Discussion}

The DLC metal base, aluminum nitride ceramics base and alumina ceramic base are adopted, in order to anaylse the effection of base material on the heat performance for high-power LED liquid packaging. The effection of the three base materials on heat performance for high-power LED by liquid packaging and traditional packaging is anaylsed comparatively. The highest temperature of LED chip is junction temperature in the paper, approximately. The LED temperature distribution of traditional packaging in different base is shown as figure 2.

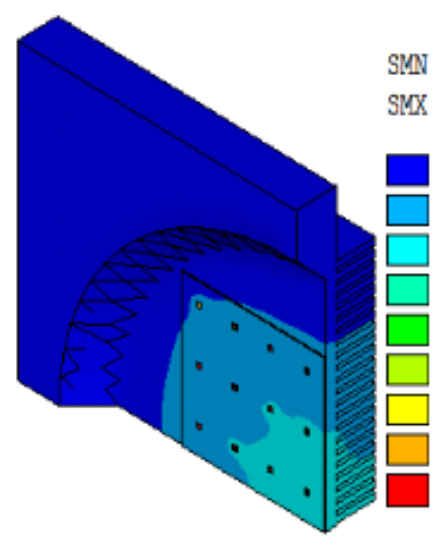

(a)

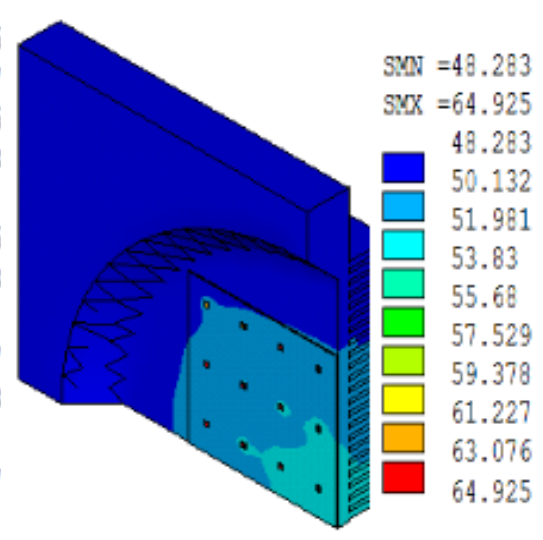

(b)

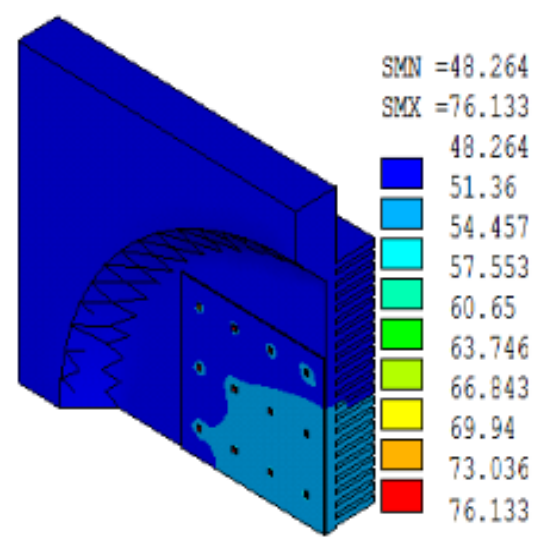

(c)

Fig.2. The LED temperature distribution of traditional packaging in different base base (b) Aluminum nitride ceramics base (c) alumina ceramic base

(a) DLC metal

The pn junction temperature of high-power LED by traditional packaging and liqulid packaging on the three kinds different base is shown as table 1. It is founded that the heat radiation effection of DLC metal base is the best, and that of alumina ceramic base is the worst, as shown in figure 2 . According to traditional packaging, the heat radiation channel is mainly from base to fins, then the heat of fins is distributed to air. The heat conduction coefficient of DLC metal base is the greatest, relatively to that of aluminum nitride ceramics base and alumina ceramic base. So, the heat radiation effection is better if the heat conduction coefficient of the base is greater. 
Table 1 LED junction temperature on different base by traditional and liquid packaging

\begin{tabular}{llll}
\hline Packaging type & $\begin{array}{l}\text { Junction temperature } \\
\text { of DLC metal }\left({ }^{\circ} \mathrm{C}\right)\end{array}$ & $\begin{array}{l}\text { Junction temperature } \\
\text { of Aluminum nitride } \\
\text { ceramics }\left({ }^{\circ} \mathrm{C}\right)\end{array}$ & $\begin{array}{l}\text { Junction } \\
\text { temperatureof } \\
\text { Aluminaceramic }\left({ }^{\circ} \mathrm{C}\right)\end{array}$ \\
\hline $\begin{array}{l}\text { Traditional } \\
\text { packaging }\end{array}$ & 63.427 & 64.925 & 76.133 \\
\hline Liquid packaging & 40.639 & 40.874 & 41.075 \\
\hline
\end{tabular}

The LED temperature distribution of liquid packaging in different base is shown as figure 3.

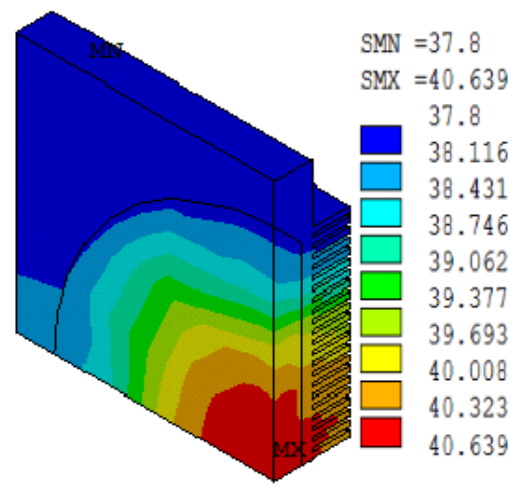

(a)

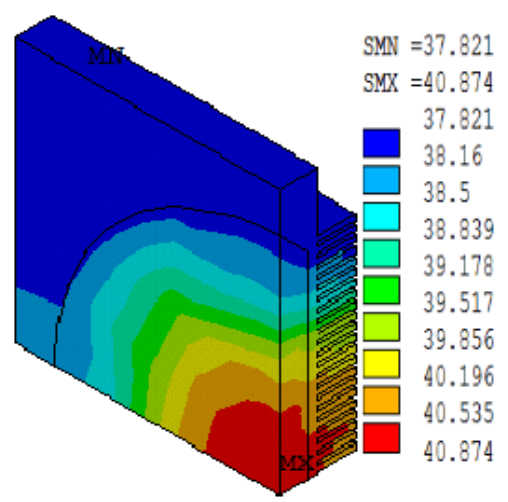

(b)

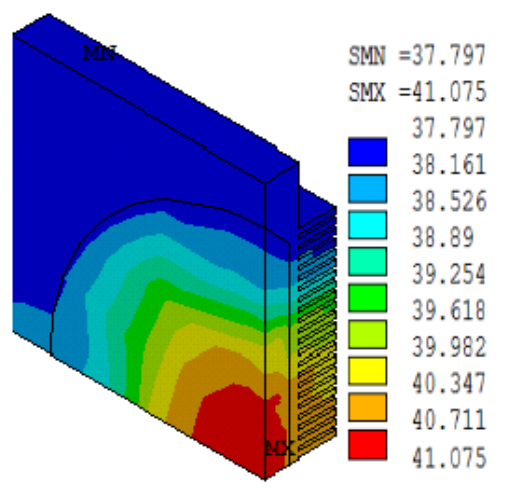

(c)

Fig.3. The LED temperature distribution of liquid packaging in different base (a) DLC metal base (b) Aluminum nitride ceramics base (c) alumina ceramic base

The simulation result shows that the pn junction temperature of high-power LED by liqulid packaging on the different base is little difference, and the junction temperature of liqulid packaging is lower, relatively to that of traditional packaging. The majority of heat of high-power LED by liqulid packaging is distributed by liquid convection, in additional to the heat radiation of base of that by traditional packaging. So, the influence of the heat conduction coefficient for the base on junction temperature is very little. The junction temperature of high-power LED by liqulid packaging can be reduced greatly, the operational life of LED can be further increased, because of the fast heat radiation.

\section{Conclusions}

The effection of DLC metal base, aluminum nitride ceramics and alumina ceramic on the heat radiation perfenanc e of high-power LED by traditional packaging and liqulid packaging has been analysed, comparatively. It is founded that the pn junction temperature of high-power LED on the three kinds base by traditional packaging has very large difference, while that by liquid packaging has little different, because the majority of heat of high-power LED by liqulid packaging is distributed by liquid convection. The LED chips can be effectively enwrapped by liqulid, the operational life of high-power LED by liqulid packaging can be effectively lengthened.

\section{Acknowledgements}

The authors would like to acknowledge the funding support by the National Natural Science Foundation of China (Grant No. 60806017 and 61136001), the Rising Industry Development Foundation of Shenzhen, China (Grant No. JCYJ20140418095735627), 973 Program of China (Grant No.2010CB635115). 


\section{References}

[1] K.C. Yung, H. Liem, H.S. Choy, Z.X. Cai, Thermal investigation of a high brightness LED array package assembly for various placement algorithms. Appl Therm.Eng. 63(2014)105-118

[2] M. Arik, J. Petroski, S. Weaver, Thermal challenges in the future generation solid state lighting applications: light emitting diodes. In: Proc IEEE intersociety conf thermal phenomena hawaii a(2002)113-120

[3] H. Minseok, Development of a thermal resistance model for chip-onboard packaging of high power LED arrays. Microelectron Reliab 32(2012)836-844

[4] S.H. Yu, K.S. Lee, S.J. Yook, Optimum design of a radial heat sink under nature convection. Int J. Heat Mass Transfer 54(2011)2499-2505

[5] Bladimir, Comparison and optimization of single-phase liquid cooling devices for the heat dissipation of high-power LED arrays. Appl. Therm. Eng.59(2013)648-659

[6] J.C. Wang, Thermal investigations on LED vapor chamber-based plate. Int. Commun. Heat Mass Transfer 38(2011)1206-1212

[7] L. Junhui, M. Bangke, W. Ruishan, H. Lei, Study on a cooling system based on thermoelectric cooler for thermal management of high-power LEDs. Microelectron Reliab 51(2011)2210-2215 